A R T I G O

\title{
PANDEMIA, “AGRO” E "SOFRÊNCIA”: JORNALISMO, PROPAGANDA E ENTRETENIMENTO NO DEBATE PÚBLICO SOBRE O MODELO AGRÍCOLA
}

Pandemic, "agro" and "sofrência": journalism, advertising and entertainment in the public debate on the agricultural model

Pandemia, "agro" y "sofrência": periodismo, publicidad y entretenimiento en el debate público sobre el modelo agrícola

LUCIANA SCHLEDER ALMEIDA ${ }^{\mathrm{I}^{*}}$

DOI: https://doi.org/10.1590/S2178-149420210208

'Universidade da Integração Internacional da Lusofonia Afro-Brasileira - São Francisco do Conde (BA), Brasil.

* Graduada em ciências sociais, com mestrado e doutorado em antropologia. Atualmente é professora adjunta do Instituto de Humanidades e Letras da Universidade da Integração Internacional da Lusofonia Afro-Brasileira e pesquisadora associada do Grupo de Pesquisa em Legislativo, Eleições e Democracia da mesma instituição. Também é pesquisadora associada do Núcleo de Antropologia da Política, ligado ao Programa de Pós-graduação em Antropologia Social do Museu Nacional da Universidade Federal do Rio de Janeiro (luciana.almeida@gmail.com).

(D) https://orcid.org/0000-0002-4800-7602

Artigo recebido em $1^{\circ}$ de janeiro de 2021 e aprovado para publicação em 31 de março de 2021. 


\title{
RESUMo
}

A pandemia jogou luz sobre a relação entre novos agentes patogênicos e a agroindústria, reanimando 0 debate sobre a obsolescência do modelo agrícola atual. A partir do contexto de reação imediata ao fato epidemiológico, esta análise concatena um conjunto de episódios midiáticos para problematizar expressões do patrimônio ideológico do agronegócio. Articulando informações obtidas na interface digital e dados etnográficos anteriores à pandemia, o texto demonstra o trabalho de atribuição de sentido a agronegócio pela apologia economicista e pelo lançamento massivo de produtos culturais associados à agricultura moderna, por meio de campanhas publicitárias e da indústria do entretenimento.

PALAVRAS-CHAVE: Agronegócio; Indústria Cultural; COVID-19.

\begin{abstract}
The pandemic shed light on the relationship between new pathogens and agribusiness, reviving the debate about the obsolescence of the current agricultural model. From the reaction context immediate to the epidemiological fact, this analysis concatenates a set of media episodes for problematize expressions of the agribusiness ideological patrimony. Articulating information obtained from the digital interface and ethnographic data prior to the pandemic, the text demonstrates the work of attributing meaning to "agribusiness" through economic apology and the launching mass of cultural products associated with "modern agriculture", through campaigns advertising and entertainment industry.
\end{abstract}

KEYWORDS: Agribusiness; Cultural Industry; COVID-19.

\section{RESUMEN}

La pandemia arrojó luz sobre la relación entre nuevos patógenos y la agroindustria, reviviendo el debate sobre la obsolescencia del modelo agrícola actual. Desde el contexto de la reacción inmediata al hecho epidemiológico, este análisis concatena un conjunto de episodios mediáticos para problematizar expresiones del patrimonio ideológico del agronegocio. Articulando información obtenida de la interfaz digital y datos etnográficos antes de la pandemia, el texto demuestra el trabajo de atribuir significado al "agronegocio" a través de la apología económica y del lanzamiento de productos culturales asociados a la "agricultura moderna", a través de campañas de publicidad y de la industria del entretenimiento.

PALABRAS CLAVE: Agronegocio; Industria Cultural; COVID-19. 
A ideia de "esgotar" as possibilidades técnicas dadas, a ideia da plena utilização de capacidades em vista do consumo estético massificado, é própria do sistema econômico que recusa a utilização de capacidades quando se trata da eliminação da fome. (Adorno \& Horkheimer, Dialética do Esclarecimento)

\section{INTRODUÇÃO}

$\mathrm{E}$ sta análise tem como ponto de partida um conjunto de eventos midiáticos vinculados à ideia de agronegócio que emergiram no noticiário econômico e no âmbito da indústria do entretenimento sob os primeiros impactos da pandemia. 0 texto problematiza dimensões variadas do patrimônio ideológico do agronegócio, entendido como a construção e a manutenção de um imaginário coletivo como estratégia de legitimação, num contexto em que vem à tona a associação entre a indústria agroalimentar e o surgimento de novas doenças infecciosas.

As notícias sobre os impactos econômicos da crise global ocasionada pela pandemia destacaram, num primeiro momento, a imunidade do mercado da soja - monocultura emblemática do agronegócio — e sua formidável contribuição para o produto interno bruto (PIB) brasileiro. A implementação das medidas de distanciamento social, a paralisação de uma ampla gama de atividades produtivas e a queda das demandas interna e externa vêm causando uma forte retração nos indicadores da indústria, do comércio e dos serviços. Contrariando essa tendência, as previsões para o PIB agropecuário são de crescimento de 1,5\% em 2020 e de 1,2\% em 2021 (IPEA, 2020).

0 distanciamento social impôs modalidades caseiras de entretenimento, como as lives: transmissões ao vivo nas quais usuários podem fazer comentários e deixar curtidas, além de acompanhar as atividades dos demais espectadores. Logo que as medidas restritivas foram adotadas no Brasil, no final de março de 2020, a repercussão desses eventos virtuais contribuía para criar algum senso de multidão, de coletividade, num momento de amedrontamento geral provocado pelo anúncio da pandemia. As mais populares lives de abril foram as apresentações de artistas do sertanejo universitário, gênero musical que surgiu nas exposições agropecuárias realizadas nas cidades médias no Centro-Oeste e no oeste de São Paulo e de Minas Gerais, que celebram a modernização agrícola. Cantoras e cantores sertanejos costumam exibir nas redes sociais um estilo de vida que combina cenários rurais (fazendas, animais de criação, pescarias) com a suntuosidade de suas residências, de seus automóveis, de suas viagens turísticas e de seus tratamentos estéticos.

Este texto tem como objetivo demonstrar como a indústria fonográfica expressa aspectos do debate nacional sobre modelo de desenvolvimento. 0 contexto da pandemia, sobretudo o momento de reação imediata ao fato epidemiológico, permite concatenar a anunciada 
subversão da crise global pelo setor do agronegócio e a afirmação do sertanejo universitário como principal produto da indústria fonográfica brasileira. 0 cruzamento entre agronegócio e sertanejo universitário revela que o aparato ideológico de justificação das atividades produtivas agroindustriais na esfera pública vai além da apologia economicista, incluindo artifícios ligados à indústria cultural. É como se o sertanejo universitário fosse a trilha sonora da guinada conservadora (Escritório Central de Arrecadação e Distribuição, 2018), que reflete o histórico compromisso do Estado brasileiro com a manutenção de uma estrutura fundiária concentrada e subserviente às demandas globais.

0 termo agronegócio tem sido usado pelos movimentos camponeses para definir variados empreendimentos agropecuários integrados ao mercado global, baseados na exploração predatória da terra e de recursos hídricos associada ao uso massivo de fertilizantes e defensivos agrícolas. Outra definição, mais ligada à importação do termo dos Estados Unidos e circulante nas associações patronais e no debate acadêmico, enfatiza a natureza de suas cadeias agroindustriais em escala global, especialmente suas conexões políticas e financeiras (Grynspan, 2012). No presente texto, essas duas perspectivas deverão compor um pano de fundo para se pensar as disputas de classificações na atribuição de sentido não somente ao agronegócio, como também à definição de agricultor.

As lives sertanejas repercutiram não somente pela grande audiência, mas também por situações inusitadas criadas por cantores bêbados e por tornarem-se palco de disputa política entre o presidente Jair Bolsonaro e o então ministro da Saúde Henrique Mandetta. No primeiro episódio, a aparição de Mandetta recomendando o distanciamento social na live da dupla Jorge e Mateus, que alcançou 3,1 milhões de acessos simultâneos, foi encarada pelo presidente como uma provocação. Na semana seguinte, o cantor Gusttavo Lima foi alvo de uma ação do ConseIho Nacional de Autorregulamentação Publicitária por apresentar-se embriagado e consumindo grande quantidade de bebidas alcoólicas em live que atingiu 2,6 milhões de acessos simultâneos. 0 presidente Jair Bolsonaro saiu em defesa do cantor, que foi seu apoiador na campanha eleitoral, numa rara menção elogiosa a um artista em suas redes sociais (Da Redação, 2020).

A identificação do governo Bolsonaro com o "agro" pode ser constatada até mesmo na logomarca oficial, que sugere um campo verde sob o Sol. Além de renovar políticas econômicas que vêm conferindo suporte ao setor, o governo vem assumindo uma postura, no mínimo, complacente, que alimenta uma criminosa ofensiva contra movimentos sociais, traduzida no maior número de assassinatos de lideranças indígenas e camponesas em dez anos (Figueiredo, 2019). A onda conservadora consolidada nas eleições de 2018 e encabeçada pelo que a crônica política apelidou de "Bancada BBB" (bala, boi e Bíblia) recrudesceu a agenda econômica predatória (em relação ao meio ambiente e aos corpos). 
A agenda econômica neoliberal encontra-se combinada com uma espécie de cruzada moral contra o que chamam de marxismo cultural, ideologia de gênero, direitos humanos e outras tendências, por assim dizer, demoníacas de artistas e intelectuais brasileiros. 0 campo da indústria cultural, portanto, assumiu centralidade no debate público, e é nesse sentido que o sertanejo universitário pode ser um tema revelador de disputas morais.

A apresentação está organizada em três eixos principais: a) destaca a relação entre o sertanejo universitário e as exposições agropecuárias; b) compreende as exposições agropecuárias como fenômenos humanos de longa duração ligadas às exposições mundiais/internacionais que surgiram no século XIX em diferentes partes do mundo; c) revela, com base em pesquisa etnográfica e revisão bibliográfica sobre as exposições contemporâneas, a reprodução de uma ideologia civilizatória, cujas raízes encontram-se no imperialismo, no colonialismo e no industrialismo.

A coleta de dados está ligada à experiência de confinamento nas primeiras semanas, num apanhado da repercussão de temas caros ao aparato de justificação na esfera pública da concertação do agronegócio (Pompeia, 2020). A análise encontra-se apoiada também em experiência etnográfica no Mato Grosso, precisamente na região da cidade de Sorriso, que se destaca como município que mais produz soja no Brasil.

\section{SERTANEJO UNIVERSITÁRIO CELEBRANDO A MODERNIDADE}

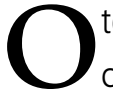
termo sertanejo universitário faz referência ao sertanejo, gênero musical que fez sucesso nos anos 1990, e o atualiza agregando universitário, que denota um elemento moderno, no sentido de estar ligado ao modo de vida urbano e à mobilidade social. Enquanto produto da indústria cultural, a imagem dos sertanejos foi construída ao longo dos anos 1970 a 1990, associada à ideia de modernização e contrastando com a imagem do caipira, que remete ao modo de vida rústico no campo (Alonso, 2011).

No início dos anos 2000, o gênero musical sofreu uma transição, com mudança na instrumentação (a sanfona no lugar do teclado, o violão com cordas de aço no lugar na guitarra elétrica) e na temática das canções (em vez da impossibilidade da realização amorosa, o amor afirmativo ou as relações passageiras ou fluídas) (Alonso, 2012). Há inclusive a absorção enviesada de protestos caros ao feminismo ligados a um subtipo do gênero, protagonizado por mulheres, chamado feminejo, ou sofrência. A crítica musical percebe nas temáticas das canções o "detalhamento de efeitos macroeconômicos da expansão da fronteira agrícola e do lulismo como exaltação do consumo, facilidade de crédito e mudanças na pirâmide social" (Paiva, 2013, p. 4). 0 apodo universitário marca esse distanciamento do sertanejo dos anos 1990, incorporando certa urbanidade, associada ao aumento significativo de instituições de ensino superior e da ampliação das matrículas nas últimas décadas. 
A emergência do gênero, como é comum em tantos outros fenômenos de popularidade, tende a ser atribuída a uma espécie de inversão, em que a indústria fonográfica consolida nomes que se tornaram populares de forma independente, na esteira das novas tecnologias. No caso do sertanejo universitário, há uma especificidade ligada ao próspero circuito de feiras agropecuárias distantes das capitais, que são palcos para esses jovens artistas, como confirmam vários estudos sobre o tema (Alem, 2005; Leal, 2008; Alonso, 2011; Chã, 2016).

A identificação do gênero musical com as feiras e exposições agropecuárias é reveladora da moralidade subjacente às aspirações modernas no campo, operando na composição de uma imagem construída do agronegócio, assim como demonstrando suas contradições. Os estudos de cunho histórico e etnográfico sobre o tema indicam que as feiras e exposições agropecuárias correspondem a festividades nas quais as elites exercem seu poder simbólico (Guimarães, 1996), a momentos de celebração e consagração de representações simbólicas dominantes na nova ruralidade brasileira, ao mesmo tempo que se apresentam como populares, promovendo espetáculos como shows musicais e rodeios (Alem, 2005), ou, ainda, como contextos em que o agronegócio emerge como um conhecimento e uma prática salvadora, que une campo e cidade, que gera empregos e que produz divisas (Leal, 2008: 40). As raízes históricas das feiras e exposições agropecuárias estão localizadas nas exposições mundiais/internacionais do século XIX e começo do século XX (Guimarães, 1996; Klug, 2012; Sandaj, 2017).

Eventos do tipo exposições mundiais proliferaram em meados do século XIX associados aos valores civilizatórios, ou ligados à ideia de progresso, em variadas modalidades de expressão: enquanto afirmação de projetos geopolíticos hegemônicos, divulgação de produtos e serviços, oportunidade de troca e intercâmbio no sentido de inovação e tecnologia, divulgação de propaganda ideológica e política, de diversão e lazer (Sandaj, 2017), palco de exibição de saberes coloniais, ou todo o conhecimento produzido tendo como referências os territórios coloniais, com fins aplicados ou não (Thomaz, 2001).

Os estudos historiográficos sobre as exposições internacionais, sobretudo a partir dos anos 1980, definem-nas como fenômenos geopolíticos da modernidade, associados à ordem burguesa que se expandia pelo mundo, aos movimentos nacionalistas e colonialistas que moldaram as relações internacionais da época e à emergência de uma rede expositiva ou de uma cultura de exposições que conectava distintos espaços e tempos da humanidade, possibilitando o desenvolvimento de um repertório e de um padrão na linguagem dessas exposições. Uma das matrizes teóricas dessas interpretações está ligada à teoria da hegemonia de Gramsci: exposições enquanto ferramentas ideológicas das classes dominantes para impor seus valores e construir o consenso social por meio da persuasão, do consentimento dos dominados, representados 
pela massa de visitantes que afluía aos eventos. Essa abordagem aparece associada a outras três, ligadas ao imperialismo, ao controle e à disciplina, que constituem a razão da ação estatal e normatização social, da indústria de massa, do consumo de massa e da cultura popular. 0 presente artigo apresenta uma contribuição etnográfica para se pensar as exposições como feiras de mercadorias e ideias que movem e conectam os visitantes no sentido de comportamentos com uma intensidade de formalidade ritual, numa espécie de peregrinação ou performance coletiva. Dessa forma, incorporamos um olhar analítico sobre as contradições constitutivas e a heterogenia no tempo e no espaço das exposições (Sandaj, 2017).

A moldura interpretativa que associa imperialismo, colonialismo e industrialismo com as exposições metropolitanas adquire outras significações nas celebrações do progresso ${ }^{1}$ realizadas na América Latina, em contexto de economias baseadas em agricultura, pecuária, extrativismo e mineração. É constante, no entanto, a extrapolação de um culto civilizatório abstrato por meio da difusão de invenções e descobertas que se tornaram símbolos de um novo e extraordinário poder de dominação da natureza (Ferreira, 2011).

Em suas participações nas exposições internacionais, o Brasil oferecia suas riquezas naturais como bilhete de acesso ao festim industrial, exibindo a imagem de uma rica nação a ser despertada pelos pioneers/empreendedores europeus (Barbuy, 1996; Sandaj, 2017). Essa apropriação simbólica do mundo natural (o solo fértil, o fruto exótico, o monocultivo, a exploração do petróleo, o cobre ou os recursos marinhos ou selvagens) pelo Estado seria uma característica recorrente dos países latino-americanos (Murillo Sandoval, 2015: 276).

Enquanto países mais industrializados apresentavam inovações ligadas à eletricidade, às máquinas à vapor, ao material de estrada de ferro, às máquinas e aos aparelhos de mecânica em geral, às máquinas-ferramentas ou, ainda, ao material e aos procedimentos de engenharia civil, de trabalhos públicos e de arquitetura, os países não industrializados, como o Brasil, reuniam coleções científicas e contribuições de comerciantes dos setores de exploração agrícola, das minas e da metalurgia, da indústria florestal (sementes e plantas de essências florestais) e da fabricação de produtos agrícolas não alimentícios (Ferreira, 2011). Conforme Sandaj (2017: 806), os estudos sobre as exposições realizadas na América Latina dão conta que:

(a) havia extrema dificuldade em elaborar discursos e construir símbolos semelhantes aos europeus, estes, centrados no desenvolvimento industrial e tecnológico, na instrução e no bem-estar social; (b) havia imprecisão - e, por vezes, ineficácia — nas imagens e mensagens articuladas em edifícios, objetos e espetáculos, quase sempre referentes ao "atraso" latino-americano, mesmo quando emulavam a "modernidade" europeia; (c) havia constrangimento, tanto no sentido de condensação, redução, quanto no de embaraço provocado por situação moralmente 
desconfortável, em apresentar a diversidade social e cultural desses países em um contexto imperialista, colonialista, racista e eurocêntrico, o que levava à idealização das populações locais em chave positiva ou negativa, mas sempre representadas de maneira a-histórica, homogeneizadas, desterritorializadas, às vezes propositalmente invisibilizadas.

Enquanto ferramentas ideológicas das classes dominantes, as exposições operam no sentido de impor seus valores e construir um clima de consenso social, transmutando interesses específicos de determinado setor do mercado em temas de interesse comum. Essa dimensão pedagógica ou disciplinadora das exposições só se realiza na medida em que esses eventos mobilizam o público formado por trabalhadores e operários, como revelam as fotos que nos restam das exposições internacionais: "Era preciso que estes se reconhecessem nos produtos saídos de suas jornadas de trabalho e que ficassem na obra da Civilização e do Progresso Mundiais. Que 'se instruíssem enquanto satisfaziam sua curiosidade', para utilizar a expressão de um contemporâneo" (Neves, 1986: 28). 0 uso de fotografias nas exposições brasileiras revela que o trabalho de construção de uma narrativa visual que reforçava a imagem de um país moderno andava pari passu do projeto de embranquecimento que enfrentava 0 atraso escravagista (Sandaj, 2017).

\section{ESTRUTURAS DA COLONIALIDADE: CONSENSO E CONTRADIÇÕES NUMA EXPOSIÇÃO CONTEMPORÂNEA}

$\mathrm{O}$ s estudos sobre as exposições contemporâneas destacam a sobreposição de interesses políticos e corporativos em escala global (Sandaj, 2017), reunindo culto às máquinas agrícolas, concursos de animais, rodeios e parques de diversões num ambiente que deve promover negócios. A mais famosa exposição agropecuária é a Festa do Peão de Boiadeiro de Barretos, no interior de São Paulo. Artistas do sertanejo universitário rivalizam anualmente pelo título de embaixador da festa.

No intuito de contribuir para a compreensão das exposições como fenômenos de longa duração, servir-nos-ão alguns dados etnográficos² sobre a feira agropecuária realizada anualmente na cidade de Sorriso, conhecida como a "capital da soja", que, desde 2011, apresenta o maior PIB agropecuário do Mato Grosso, alternando o segundo lugar com os municípios Sapezal e Campo Novo do Parecis (dados do Instituto Brasileiro de Geografia e Estatística). A área estudada foi aberta, nos anos 1970, por frentes pioneiras, ou formas de ocupação territorial economicamente organizadas, seja por empresas agrícolas, seja pela agricultura familiar e comercial (Martins, 1975). A soja tem operado como cultivo estratégico no avanço dessas frentes, alçando o país à posição de principal país produtor: os dados da safra 2019/20 
apontam que o Brasil é responsável por aproximadamente $37 \%$ da soja produzida $(124,845$ milhões de toneladas) (Embrapa, 2020).

0 desencadear de duradouros e intensos fluxos populacionais introduziu formas de ocupação modernas da terra, fazendo surgir, muito rapidamente, lavouras e núcleos urbanos sobre áreas de floresta então parcamente habitadas, pontuadas por seringais, garimpos e fazendas de pecuária extensiva. A população preestabelecida de comunidades ribeirinhas e indígenas foi sendo impelida a abandonar seus territórios em virtude de uma série de políticas que favoreciam a fixação de população exógena num movimento de colonialismo interno (Casanova, 2007). Nos anos 1980, as experiências com a soja começaram a mostrar-se promissoras, e, nos anos 2000, a região Centro-Oeste superou a região Sul na produção nacional do produto, sendo o Mato Grosso, atualmente, o principal estado produtor. Além dos colonos vindos do Sul, a área também passou a receber, sobretudo a partir dos anos 1990, importante contingente de trabalhadores do Norte.

As famílias de colonos pesquisadas compartilham o mesmo estilo de arrogação pioneira e identificam-se como "gaúchas": denominação adotada pelos colonos 3 no processo de deslocamento para a nova área. São considerados gaúchos não somente produtores, mas também prestadores de serviços, vendedores de insumos e comerciantes da cidade. A população não gaúcha costuma ser identificada como "maranhense" (trabalhadores vindos do Norte) e "cuiabana" (a população de origem mato-grossense) ${ }^{4}$. A distinção entre gaúchos e não gaúchos encontra-se inscrita na flagrante segregação socioespacial que caracteriza a cidade, entendida por seus habitantes como uma cidade dividida pela BR-163 (Almeida, 2021).

A data da Exporriso, na segunda semana de maio, além de aludir à emancipação do município em 1986, também coincide com o final da colheita da soja. Não por acaso, até o final dos anos 1990, era chamada Festa do Chimarrão e da Soja. Desde sua criação, a festa é sediada no clube Centro de Tradições Gaúchas (CTG). Somente por ocasião da grande festa, cujo slogan era "Tudo mundo vai", os trabalhadores maranhenses circulavam nas dependências do clube.

A festa era muito aguardada pela população da cidade. Havia grande expectativa em relação às atrações musicais, um dos quesitos importantes na comparação entre as feiras do mesmo tipo nas cidades vizinhas: Expolucas (Lucas do Rio Verde), Exposinop (Sinop), Expomutum (Nova Mutum). As datas das feiras não coincidiam, de modo que era comum que os jovens se deslocassem de uma cidade para outra, sobretudo em função dos shows. Na noite da abertura, enquanto os fogos de artifício anunciavam o início da feira, já era possível observar, nas ruas próximas ao CTG, que parte do público chegava a pé, oriundo dos bairros periféricos, e outra parte, identificada como o público gaúcho, chegava em automóveis, que lotavam um amplo estacionamento. 
Na área por onde todos deveriam passar, logo à entrada, estavam instalados os estandes de estabelecimentos comerciais dos mais diversos: desde piscinas até roupas, artigos para animais de estimação, construtoras, erva-mate, móveis, eletroeletrônicos, motocicletas. Associações filantrópicas formadas por famílias de produtores e profissionais liberais também buscavam visibilidade organizando estandes para vender galetos como forma de arrecadar fundos.

Além dos shows, a exposição de máquinas agrícolas exercia forte apelo entre o público. As colheitadeiras e os pulverizadores, toda sorte de tratores, ficavam dispostos, devidamente limpos e reluzentes. Famílias, casais, grupos de adolescentes passavam observando sem pressa. Os homens e as crianças demonstravam mais entusiasmo pelas máquinas, que também eram pano de fundo preferido para as fotos infantis.

Nesses setores principais, os diferentes públicos aparentemente misturavam-se, assim como no momento dos grandes shows, mas também havia partes em que o contraste entre os públicos gaúcho e maranhense ficava mais evidente. Havia, por exemplo, um setor da feira que, segundo um dos sócios do CTG, era conhecido como Peixotinho, aludindo a Peixoto de Azevedo, município ao norte do Mato Grosso, de onde vinham muitos dos trabalhadores chamados maranhenses. Tratava-se de uma área repleta de bancas de bebidas, pastéis, crepes e sorvetes, que se destacava pelas luzes coloridas da decoração e pela música eletrônica em alto volume. Jovens aglomeravam-se entre as barracas, dançando, conversando, bebendo. Também se escutava forró vindo de outros bares, com mesas e televisões instaladas. Afastadas dos caminhos onde estavam as tendas e por onde o público passava, havia algumas barracas de acampamento que as pessoas que trabalhavam naquele setor utilizavam para dormir.

Outros contextos nos quais emergia esse contraste entre os diferentes públicos reunidos na feira eram os bailões que aconteciam à noite, mesclando forró, música gauchesca e sertanejo. Nas noites de forró, podia-se observar casais em passos mais lânguidos, e não tão rodopiados para frente e para trás como na dança dos gaúchos. 0 público identificado como maranhense tomava a pista de dança, e os casais gaúchos permaneciam em áreas mais periféricas do salão, mais bebendo e conversando do que dançando.

Quando observamos a paisagem sonora das exposições, fica evidente que as tendências disciplinadoras das exposições não obliteram a expressão das contradições do capitalismo, do colonialismo e do industrialismo. Ao mesmo tempo que elaboravam hierarquias sociais e distanciamento do que era considerado o gosto civilizado (o europeu) e o primitivo (o exótico), esses eventos criaram condições de resistência e contestação da autoridade imperial por meio da música e da forma como ela era executada, em claras demonstrações de pertencimento e orgulho racial ou social (Fauser apud Sandaj, 2017). 
Nota-se o jogo entre consenso e contradições no conjunto da paisagem sonora da feira. Além das apresentações de maior apelo popular, como artistas do sertanejo universitário e outros de renome nacional, a feira inclui momentos destinados a atrações mais ligadas ao estilo gauchesco e ao forró, identificado com os trabalhadores maranhenses. A imagem do público gaúcho observando o baile dos maranhenses tanto remete a uma configuração exotizante do outro, como sugere demonstrações de pertencimento e orgulho racial ou social.

Os rodeios também são modalidades de entretenimento que mobilizam público diversificado. Aqui, no entanto, pude observar que o contraste fica mais manifesto entre cavaleiros gaúchos e cuiabanos. 0 marcador mais evidente entre os dois públicos está nas vestimentas: os cuiabanos vestem calças justas, não as bombachas dos gaúchos, e o chapéu com a copa redonda, no estilo pantaneiro. Nos rodeios de Sorriso, os cuiabanos eram considerados favoritos aos prêmios.

Entre as atrações das exposições contemporâneas, chamadas aqui de feiras agropecuárias, os rodeios podem ser considerados modalidades de espetáculo muito ligadas ao contexto das Américas. Os estudos sobre as exposições internacionais pouco ou nada mencionam sobre a exposição de animais, sendo mais frequente a referência à exaltação das máquinas e à exibição de populações colonizadas de todo o mundo como semi-humanas, num projeto de racionalização antropológica.

Os rodeios são competições esportivas que cultuam a imagem do peão de boiada, mais uma das variações do herói a cavalo ligado à expansão territorial. A modalidade mais conhecida nos rodeios é aquela em que o competidor monta um touro, que é induzido a pular por uma cinta tracionada em volta do abdômen. Esse desejo de controle sobre as forças da natureza corresponde a uma referência modernizante fundamental no aprimoramento tecnológico do agronegócio e no avanço sobre novas áreas. A memória e a permanência do pacto em torno do colonialismo interno encontram-se associadas à otimização das formas de exploração dos recursos, algo elaborado moralmente enquanto dominação das forças da natureza, para a qual a pesquisa científica e o aperfeiçoamento técnico são essenciais. 0 furor científico das exposições fica evidente na constância do culto às máquinas como símbolos da racionalização técnica do trabalho e da produção baseada num enquadramento moral que permite 0 ataque e a violação da Mãe Terra, como se os homens com suas máquinas fossem capazes de tornarem-se independentes da natureza, bem como das mulheres (Merchant, 1993: 270).

\section{DisPUTA DE CLASSIFICAÇÕES: O “AGRO” SEM “NEGÓCIO”}

\footnotetext{
A s exposições internacionais são consideradas "a mídia mais popular e poderosa do Aséculo XIX" (Geppert apud Sandaj, 2017: 795), e esse poder de difusão continua
} 
operando no início do século XXI. 0 tema de uma recente exposição internacional realizada na cidade de Milão em 2015, que teve como lema "Alimentar o planeta, energia para a vida", atraiu 150 países e 20 milhões de visitantes. 0 evento, que celebrou a diversidade cultural, a alimentação saudável e o desenvolvimento sustentável, foi patrocinado por multinacionais da indústria agroalimentar (Sandaj, 2017). 0 investimento em publicidade é proporcional à massa crítica dos atuais padrões da produção de alimentos em larga escala.

A crise pandêmica da COVID-19 lançou luz sobre os aspectos deletérios das técnicas utilizadas na criação de animais e as condições insalubres das plantas de processamento de carnes (Segata, 2020), bem como suscitou reflexões mais amplas relacionadas à forma como a sociedade moderna organiza suas atividades produtivas. São numerosos os estudos que indicam a ligação direta ou indireta dos surtos de novas doenças e das mudanças na produção ou no uso do solo associadas à monocultura intensiva — tanto a pecuária quanto a agricultura (Wallace, 2020). Nas últimas três décadas, expressões como mal da vaca louca, gripe suína e gripe aviária ganharam o noticiário internacional.

A novidade epidemiológica emergiu num contexto em que o setor do agronegócio já vinha sofrendo desgaste em função do aumento expressivo dos indicadores relacionados ao desmatamento da Amazônia em 2019 (Oliveira, 2019). A divulgação dos dados oficiais compilados pelo Instituto Nacional de Pesquisas Espaciais (Inpe) foi o estopim de um dos embates entre o governo federal e a comunidade científica, culminando na exoneração do então diretor do instituto, o físico Ricardo Galvão. 0 episódio repercutiu internacionalmente, sendo o ex-diretor incluído na prestigiada lista dos dez cientistas que mais se destacaram no ano, sob o título de defensor da ciência (Tollefson, 2019). Em 2020, as áreas de conservação permaneceram em seu estado de vulnerabilidade, quando o país acompanhou pelo noticiário os dramáticos incêndios florestais, não somente na Amazônia, como também no Pantanal (o maior em três décadas) (Lemos, 2020).

No noticiário, as causas dos desastres ambientais foram atribuídas à estiagem histórica e ao agronegócio. A intensificação costumaz das queimadas do mês de agosto foi ainda mais acentuada, e veio à tona uma mobilização para desmatar, conhecida como Dia do Fogo, ocorrida no Pará a partir de municípios às margens da BR-163 em 10 de agosto de 2019 (Almeida, 2019). Os números do Inpe sobre a incidência de queimadas em 2020 foram piores que os do ano anterior (Instituto Nacional de Pesquisas Espaciais, 2021). Em julho de 2020, recebeu destaque na imprensa internacional um estudo na revista Science demonstrando que 18 a 22\% de toda a soja exportada da Amazônia e do Cerrado para a União Europeia poderia estar contaminada com desmatamento ilegal (Rajão, 2020: 3). 
No debate a respeito do modelo de desenvolvimento nacional, o argumento economicista sempre vem à baila quando o objetivo é relativizar a crise ambiental. Nesse sentido, a aclamada capacidade do agronegócio em gerar divisas, mesmo em circunstâncias de crise global, corresponde a um argumento recorrente. Em 2008, havia um consenso de que 0 mercado global estava em crise, e, assim como observamos hoje, o setor do agronegócio figurou como bastião da economia nacional (Canal Rural, 2009). É importante notar que essa imunidade às crises globais não seria possível sem o aporte estratégico do Estado, traduzido pela política de ordenamento territorial, trabalhista, ambiental, de crédito, infraestrutura etc. (Leite e Wesz Junior, 2016). Naquela ocasião, o compromisso do governo com o agronegócio ficou evidente no reposicionamento do Movimento dos Trabalhadores Rurais Sem Terra (MST), que se retirou de boa parte dos conselhos federais que compunham o sistema de participação social e rejeitou a presença do presidente no $5^{\circ}$ Congresso do MST, realizado em 2007 (Comerford et al., 2014). João Pedro Stédile, da direção nacional do movimento, declarou à época que se tratava de uma resposta à defesa de interesses do agronegócio e de banqueiros (Azevedo, 2020). Dentro do governo, essa movimentação também ficou evidente em maio de 2008, quando Marina Silva deixou o Ministério do Meio Ambiente mencionando "necessária a reconstrução da sustentação política para a agenda ambiental" em sua carta de demissão (Uol Notícias, 2008). Quatro anos depois, o Congresso Nacional aprovou o Novo Código Florestal Brasileiro, que significou uma rotunda vitória dos segmentos ligados ao agronegócio. A cruzada da bancada ruralista hoje mira os direitos territoriais das populações indígenas e comunidades tradicionais.

A campanha publicitária "Agro é tudo" traduz a determinação das organizações patronais em garantir a construção de uma boa reputação do agronegócio, a despeito das controvérsias relacionadas à crise ambiental potencializadas pela pandemia. Essa reação está ligada também ao esforço de superdimensionamento do tamanho do agronegócio na economia, apesar de sua dimensão política mais restrita (Pompeia, 2020: 209). Além de operarem como estratégias de legitimação nas quais interesses do setor da agroindústria são apresentados como interesses de toda a população (Bruno, 2012), as peças publicitárias difundidas buscam reforçar a identificação da imagem do agricultor aos agentes do agronegócio, obliterando a dimensão mercadológica da produção agroindustrial. 0 trabaIho de construção da marca "agro" renega o negócio, de forma a escamotear a financeirização das operações e a ameaça que isso significa para a segurança alimentar da população. Em meados de 2020, essa narrativa foi abalada pela alta de preços da cesta básica, especialmente do arroz, revelando que a carreira promissora dos produtores não condiz com a garantia do poder aquisitivo para a população. 


\section{CONSIDERAÇÕES FINAIS}

Ananga duração forjadas no intuito de promover uma concepção eurocêntrica sobre o mundo cuja materialidade reside nas formas de dominação colonialista em sua configuração do século XIX. Essa herança encontra-se inscrita na ausência ou mesmo na recusa de referências culturais não brancas nessas performances artísticas identificadas com o sertanejo universitário. Essa afirmação hegemônica, no entanto, não opera sem contradições. Percebemos que a paisagem sonora das exposições e feiras agropecuárias comporta variados gêneros musicais, que expressam consensos, associados ao sertanejo universitário, e contradições, como é possível notar nos bailes animados pelo ritmo do forró.

0 culto às máquinas e os rodeios também são elementos que exercem forte atração sobre o público. Aqui encontram-se mais explícitas mensagens que remetem ao domínio da natureza pelo homem. Enquanto o maquinismo é um traço comum das exposições dos séculos XIX e XXI, os rodeios parecem ser modalidades de entretenimento mais identificadas com o contexto das Américas, onde se encontra em curso 0 avanço sobre novas áreas sob a lógica do colonialismo interno. A performance do peão sobre o boi indômito expressa essa fé nos valores da modernidade, em que a natureza é desbravada pelos recursos tecnológicos em nome do progresso.

O surgimento da pandemia impõe uma reflexão sobre a obsolescência da produção agroindustrial em larga escala, fortalecendo as teses agroecológicas defendidas pelos movimentos camponeses, que evidenciam a necessidade de se refundar a produção de alimentos. Ao mesmo tempo, notamos a explicitação dos variados artifícios no sentido de legitimação das atividades produtivas ligadas ao agronegócio. Notamos que o argumento econômico se encontra articulado com estratégias de publicidade e entretenimento que disputam projetos de sociedade nacional. 0 fenômeno de popularidade do sertanejo universitário, assim como outros produtos culturais vinculados ao mundo das exposições e feiras agropecuárias, como os rodeios e o culto às máquinas, corresponde a elementos que compõem esse enquadramento moral das concepções modernizantes sobre o rural.

Conflitos de interesse: nada a declarar.

Fonte de financiamento: A pesquisa etnográfica foi realizada no âmbito do Projeto de Pesquisa "Sociedade e Economia do Agronegócio" (2007-2014) e teve financiamento da Coordenação de Aperfeiçoamento de Pessoa de Nível Superior, do Conselho Nacional de Desenvolvimento Científico e Tecnológico e da Fundação Ford. 


\section{NOTAS}

1 Conforme Ferreira (2011: 35): " . . .as exposiç̧̃es foram chamadas de 'celebrações do progresso' por literatos, cronistas e jornalistas que as descreveram - a exemplo do repórter do Jornal do Commercio que viajou a Londres para cobrir a inauguração da Exposição de 1851 - como 'eventos únicos' alçados à categoria de 'monumentos modernos da engenhosidade humana'".

2 As informações contidas neste artigo dizem respeito ao trabalho de campo realizado na edição de 2008.

30 termo colono está sendo usado aqui num sentido genérico, em referência à população destinada a ocupar as novas áreas, conforme política de colonização oficial.

4 Os termos gaúcho, maranhense e cuiabano serão utilizados no restante do texto com os sentidos aqui especificados, dispensando o uso de aspas.

\section{REFERÊNCIAS BIBLIOGRÁFICAS}

ALEM, J. M. Rodeios: a fabricação de uma identidade caipira-sertanejo-country no Brasil. Revista USP, São Paulo, n. 64, p. 94-121, 2005. https://doi.org/10.11606/issn.2316-9036.v0i64p94-121

ALMEIDA, A. W. B. As estratégias de exportação agromineral e a usurpação das terras tradicionalmente ocupadas: à guisa de Introdução. In: ALMEIDA, A. W. B. et al. (orgs.). Mineração e Garimpo em Terras tradicionalmente ocupadas: conflitos sociais e mobilizações étnicas. Manaus: UEA Edições/ PNCSA, 2019. p. $47-70$.

ALMEIDA, L. S. Significados locais da colonização interna no norte mato-grossense. Revista Brasileira de Estudos Urbanos e Regionais, v. 23, 2021. https://doi.org/10.22296/2317-1529.rbeur.202101

ALONSO, G. Cowboys do asfalto: música sertaneja e modernização brasileira. 2011. 528f. Tese (Doutorado em História) - Universidade Federal Fluminense, Rio de Janeiro, 2011.

ALONSO, G. O Sertão vai à faculdade: o sertanejo universitário e o Brasil dos anos 2000. Revista Perspectiva Histórica, Salvador, n. 2, p. 99-111, 2012.

AZEVEDO, R. MST, uma estética, uma ética... Veja, atualizado 31 jul. 2020. Disponível em: <shttps://veja. abril.com.br/blog/reinaldo/mst-uma-estetica-uma-etica-8230/>. Acesso em: 5 fev. 2021.

BARBUY, H. O Brasil vai a Paris em 1889: um lugar na Exposição Universal. Anais do Museu Paulista, São Paulo, v. 4, n. 1, p.211-261, 1996. https://doi.org/10.1590/S0101-47141996000100017

BRUNO, R. Movimento Sou Agro: marketing, habitus e estratégias de poder do agronegócio. In: ENCONTRO ANUAL DA ANPOCS, 36., set. 2012, Fortaleza. Anais [...]. Fortaleza, 2012. Disponível em: <http://portal. anpocs.org/portal/>. Acesso em: 2 fev. 2021.

CANAL RURAL. Exportações do agronegócio crescem 24\% em 2008 apesar da crise, 12 fev. 2009. Disponível em: <https://www.canalrural.com.br/noticias/exportacoes-agronegocio-crescem-2008-apesar-crise-47819/>. Acesso em: 3 fev. 2021. 
CASANOVA, P. G. Colonialismo interno (uma redefinição). In: BORÓN, A. et al. A teoria marxista hoje. São Paulo: CLASCO, 2007, p. 431-458. Disponível em <http://bibliotecavirtual.clacso.org.ar/clacso/formacionvirtual/20100715084802/cap19.pdf>. Acesso em: 21 fev. 2018.

CHÃ, A. M. J. Agronegócio e indústria cultural: estratégias das empresas para a construção da hegemonia. 2016. 159f. Dissertação (Mestrado em Desenvolvimento Territorial na América Latina e Caribe) - Universidade Estadual Paulista "Júlio de Mesquita Filho", São Paulo, 2016.

COMERFORD, J. C. et al. 0 mundo da participação e os movimentos rurais: entre mobilizações, espaços de interlocução e gabinetes. In: HEREDIA, B.; LEITE LOPES, J. S. (orgs.). Movimentos sociais e esfera pública: 0 mundo da participação. Rio de Janeiro: CBAE/UFRJ, 2014. p. 67-99.

DA REDAÇÃO. Bolsonaro defende Gusttavo Lima e diz que cantor foi "covardemente atacado". Istoé, Edição 2670, 17 abr. 2020. Disponível em: <https://istoe.com.br/bolsonaro-defende-gusttavo-lima-e-diz-que-cantorfoi-covardemente-atacado/>. Acesso em: 3 fev. 2021.

EMPRESA BRASILEIRA DE PESQUISA AGROPECUÁRIA. Soja em números. Disponível em: <https://www. embrapa.br/soja/cultivos/soja1/dados-economicos>. Acesso em: 30 ago. 2020. ESCRITÓRIO CENTRAL DE ARRECADAÇÃO E DISTRIBUIÇÃO. ECAD comprova: sertanejo é o ritmo mais ouvido no Brasil. Ecad, 11 dez. 2018. Disponivel em: <https://www3.ecad.org.br/em-pauta/Paginas/ecad-comprova-sertanejo-e-o-ritmomais-ouvido-no-brasil.aspx $\geq$. Acesso em: 3 fev. 2021.

FERREIRA, C. E. Difusão do conhecimento científico e tecnológico no Brasil na segunda metade do século XIX: a circulação do progresso nas exposições universais e internacionais. 2011. 299f. Tese (Doutorado em História das Ciências e da Saúde) - Casa de Oswaldo Cruz/Fiocruz, Rio de Janeiro, 2011.

FIGUEIREDO, P. Número de mortes de lideranças indígenas em 2019 é o maior em pelo menos 11 anos, diz Pastoral da Terra. G1, 10 dez. 2019. Disponível em: <https://g1.globo.com/natureza/noticia/2019/12/10/ mortes-de-liderancas-indigenas-batem-recorde-em-2019-diz-pastoral-da-terra.ghtml?fbclid=|wAR11Z1jwDI JnJXdnLj082NfqzHq-myW70PRflp62JZIr6z8QKkBfthdnT4A>. Acesso em: 3 fev. 2021.

GRYNSPAN, M. Origens e conexões norte-americanas do agribusiness no Brasil. Revista Pós Ciências Sociais, São Luís, v. 9, n. 17, p. 1-26, 2012.

GUIMARÃES, D. M. P. A celebração da modernidade: a feira e a festa nas exposiç̃eses agropecuárias do nordeste paulista. 1996. 21 1f. Tese (Doutorado em História Social) - Universidade de São Paulo, São Paulo, 1996.

INSTITUO NACIONAL DE PESQUISAS ESPACIAIS. Queimadas: monitoramento dos focos ativos por estado. 2021. Disponível em: <http://queimadas.dgi.inpe.br/queimadas/portal-static/estatisticas_estados/>. Acesso em: 3 mar. 2021.

INSTITUTO DE PESQUISA ECONÔMICA APLICADA. Economia Agrícola. Carta de Conjuntura, número 47, $2^{\circ}$ Trimestre 2020. Brasília: IPEA, 2020.

KLUG, J. A Exposição Nacional do Rio de Janeiro (1875) e os seus impactos na produção agropecuária e nas ciências naturais. In: NODARI, E. S.; KLUG, J. (orgs.). História Ambiental e Migrações. São Leopoldo: Oikos, 2012. p. 139-150.

LEAL, N. S. "É de agronegócio!": circuitos, relações e trocas entre peões de manejo, peões de rodeio e tratadores de gado em feiras agropecuárias. 2008. 174f. Dissertação (Mestrado em Antropologia Social) Universidade de São Paulo, São Paulo, 2008 http://doi.org/10.11606/D.8.2008.tde-07042009-162728

LEITE, S. P.; WESZ JUNIOR, V. J. Políticas públicas para o financiamento do agronegócio no Brasil: programas, instrumentos e resultados com ênfase no caso de Mato Grosso. In: BÜHLER, E. A.; GUIBERT, M.; OLIVEIRA, V. L. (Comps.). 
Agriculturas empresariais e espaços rurais na globalização: abordagens a partir da América do Sul. Porto Alegre: Editora da UFRGS, 2016. p. 104-124.

LEMOS, V. Por que Pantanal vive 'maior tragédia ambiental' em décadas. BBC News Brasil, 5 ago. 2020. Disponível em: <https://www.bbc.com/portuguese/brasil-53662968z. Acesso em: 10 jan. 2021.

MARTINS, J. S. Capitalismo e tradicionalismo. São Paulo: Livraria Pioneira, 1975.

MERCHANT, C. The death of nature. In: ZIMERMANN, M. et al. (ed.). Environmental Philosophy: from animal rights to radical ecology. Nova Jersey: Pearson/Prentice-Hall, 1993. p. 269-278.

MURILLO SANDOVAL, J. D. De lo natural y lo nacional: representaciones de la naturaleza explotable en la Exposición Internacional de Chile de 1875. Historia (Santiago), 2015, v. 48, n. 1, p. 245-276. http://dx.doi. org/10.4067/S0717-71942015000100007

NEVES, M. As vitrines do progresso. Rio de Janeiro: PUC-Rio/FINEP/CNPq, 1986.

OLIVEIRA, E. Balanços oficiais de desmatamento da Amazônia confirmam dados de sistema de alerta; entenda. G1, 18 ago. 2019. Disponível em: <https://g1.globo.com/natureza/noticia/2019/08/18/balancos-oficiais-dedesmatamento-da-amazonia-confirmam-dados-de-sistema-de-alerta-entenda.ghtml>. Acesso em: 5 fev. 2021.

PAIVA, M. R. Sertanejo universitário por quê?. Estadão, 24 fev. 2013. Disponível em: <https://cultura.estadao. com.br/blogs/marcelo-rubens-paiva/sertanejo-universitario-por-que/>. Acesso em: 3 fev. 2021.

POMPEIA, C. "Agro é tudo": simulações no aparato de legitimação do agronegócio. Horizontes Antropológicos, v. 26, n. 56, p. 195-224, ago. 2020. Disponível em: <>https://www.scielo.br/pdf/ha/v26n56/1806-9983ha-26-56-195.pdf. Acesso em: 6 fev. 2021.

POMPEIA, C. Concertação e poder: o agronegócio como fenômeno político no Brasil. Revista Brasileira de Ciências Sociais, v. 35, n. 104, p. e3510410, 2020. http://dx.doi.org/10.1590/3510410/2020

RAJÃO, R. et al. The rotten apples of Brazil's agribusiness. Science, v. 369, n. 6501, p. 246, 2020. https://doi. org/10.1126/science.aba6646

SANDAJ, N. Exposições internacionais: uma abordagem historiográfica a partir da América Latina. História, Ciências, Saúde - Manguinhos, v. 24, n. 3, p. 785-826, 2017. https://doi.org/10.1590/s010459702017000300013

SEGATA, J. et al. A Covid-19 e o capitalismo na carne. Tessituras, Pelotas, v. 8, n. 1, p. 1-20, 2020. https:// doi.org/10.15210/tes.v8i1.19730

THOMAZ, O. R. "O bom povo português": usos e costumes d'aquém e d'além-mar. Mana, v. 7, n. 1, p. 55-87, 2001. https://doi.org/10.1590/50104-93132001000100004

TOLLEFSON, J. R. G: Science defender. Nature's 10 - Ten people who mattered in science in 2019. 2019. Disponível em: <https://www.nature.com/immersive/d41586-019-03749-0/index.html>. Acesso em: 10 jan. 2021.

UOL NOTÍCIAS. Leia a carta de Marina ao presidente Lula, 13 maio 2008. Disponível em: <https://noticias. uol.com.br/ultnot/2008/05/13/ult23u2297.jhtm>. Acesso em: 7 fev. 2021.

WALLACE, R. Pandemia e Agronegócio. São Paulo: Elefante, 2020. 